\title{
The Effects of Screw Arris Cross Section Shapes on the Melting Process in the Melt Conveying Section of a PVC Wood-Plastics Single-Screw Extruder
}

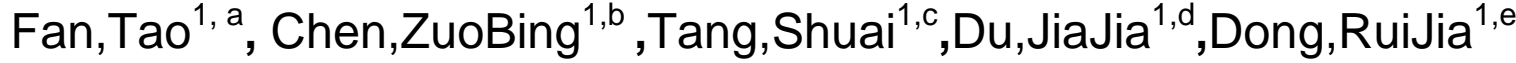 \\ ${ }^{1}$ School of Mechanical and Electrical Engineering, Wuhan University of Technology, Wuhan 430070 \\ a38315354@qq.com, b13971186965@163.com, c'straytong@sina.com, d964264106@qq.com, \\ e 283998650@qq.com
}

Keywords: PVC wood-plastics; single-screw extruder; spiral groove depth; melt conveying section; flow field.

Abstract. In this paper, a three-dimensional model of the melt conveying section of a PVC Wood-Plastic single-screw extruder has been constructed and the corresponding mesh file has been established through Mesh Superposition Techniques (MST). Then the rheological experimental results and material viscosity model parameters obtained by polymath software have been finally used for numerical simulations which are based on Polyflow software package with PVC wood plastics as raw materials. With the contrastive discussions of the simulation results, the effects of screw arris cross section shapes on the flow fields in the melt conveying section of the PVC wood-plastics single-screw extruder have been analyzed.

\section{Introduction}

Wood plastic composites ${ }^{[1-3]}, 20 \% \sim 85 \%$ wood powder and processing additives added in plastic matrix $^{[4]}$, granulated by high-speed mixer, is a vigorous rise of new type of composite materials in recent years. Wood plastic composite takes advantages of both wood and plastic. It is widely used because of its wide scope, big application market and a good economic and social benefits. The material can be shaped up in many ways such as extrusion, hot-pressing, die pressing and injection. Extrusion is extremely widely applied for its stable quality, low cost and relatively few investment. At present, wooden plastic extrusion device is forming on the basis of plastic extrusion equipment basing on the former experience. As a matter of fact the processing performance, heat transfer performance and the rheological features of wood plastic composites have great differences from ordinary plastic, which in turn led to the transformation of the equipment's low production efficiency, high energy consumption, low qualified product rate and large labor intensity. Therefore, it is high time for us to optimize and improve the existing equipment. ${ }^{[5]}$ The paper takes screw arris cross section shape as the research object. The effect of screw arris cross section shape on melt conveying section melting process can be obtained by contrasting the results of numerical simulations, which will be a guidance in optimization and improvement of screw parameters of PVC wood-plastics single-screw extruder. ${ }^{[6-9]}$

\section{Model}

\section{Mathematical model}

In view of the complexity of the melting flow in the extrusion molding process of the wood PVC wood-plastic composites, we can make assumptions in comprehensive of some factors such as geometric shapes of screw and port, material properties, flow features, as well as processing conditions ${ }^{[10-12]}$ : (1) Melt is non-Newtonian sticky fluid that cannot be compressed; (2) Flow is non-isothermal stable laminar flow field; (3)The volume forces like inertial force and gravity are ignored as a result of the high viscosity of melt; (4) There is no slip between the melt and port.

The melt flow must satisfy the three basic equation of fluid dynamics, i.e., mass conservation equation (continuity equation), momentum conservation equation (motion equation) and energy 
conservation equation. According to the above assumptions, continuity equation and movement equation of melt flow can be simplified as follows:

(1)Continuity equation

$$
\frac{\partial v_{x}}{\partial x}+\frac{\partial v_{y}}{\partial y}+\frac{\partial v_{z}}{\partial z}=0
$$

(2)Motion equation

$$
\left.\begin{array}{l}
x \text {-component }: \frac{\partial p}{\partial x}+\frac{\partial \tau_{x x}}{\partial x}+\frac{\partial \tau_{y x}}{\partial y}+\frac{\partial \tau_{z x}}{\partial z}=0 \\
y \text {-component }: \frac{\partial p}{\partial y}+\frac{\partial \tau_{x y}}{\partial x}+\frac{\partial \tau_{y y}}{\partial y}+\frac{\partial \tau_{z y}}{\partial z}=0 \\
z \text {-component }: \frac{\partial p}{\partial z}+\frac{\partial \tau_{x z}}{\partial x}+\frac{\partial \tau_{y z}}{\partial y}+\frac{\partial \tau_{z z}}{\partial z}=0
\end{array}\right\}
$$

(2)

(3)Energy equation

$$
\begin{aligned}
& \rho C_{p}\left[\frac{\partial T}{\partial t}+v_{x} \frac{\partial T}{\partial x}+v_{y} \frac{\partial T}{\partial y}+v_{z} \frac{\partial T}{\partial z}\right]=-\left[\frac{\partial q_{x}}{\partial x}+\frac{\partial q_{y}}{\partial y}+\frac{\partial q_{z}}{\partial z}\right]+\left[\tau_{x x} \frac{\partial v_{x}}{\partial x}+\tau_{y y} \frac{\partial v_{y}}{\partial y}+\tau_{z z} \frac{\partial v_{z}}{\partial z}\right] \\
& +\left[\tau_{x y}\left(\frac{\partial v_{x}}{\partial y}+\frac{\partial v_{y}}{\partial x}\right)+\tau_{y z}\left(\frac{\partial v_{y}}{\partial z}+\frac{\partial v_{z}}{\partial y}\right)+\tau_{z x}\left(\frac{\partial v_{z}}{\partial x}+\frac{\partial v_{x}}{\partial z}\right)\right]+\rho s
\end{aligned}
$$

\begin{tabular}{|c|c|c|c|c|c|c|c|c|c|}
\hline \multicolumn{6}{|c|}{ Screw melt conveying section parameters } & \multicolumn{4}{|c|}{ Melt flow region parameters } \\
\hline Model & Length(mm) & $\begin{array}{l}\text { Screw slot } \\
\text { depth(mm) }\end{array}$ & $\begin{array}{c}\text { Screw } \\
\text { normal } \\
\text { width }(\mathrm{mm})\end{array}$ & $\begin{array}{l}\text { Screw arris } \\
\text { cross } \\
\text { section } \\
\text { shape }\end{array}$ & $\begin{array}{l}\text { Study } \\
\text { object }\end{array}$ & Model & $\begin{array}{c}\text { Inside } \\
\text { diameter(mm) }\end{array}$ & $\begin{array}{c}\text { Outside } \\
\text { diameter(mm) }\end{array}$ & Length(mm) \\
\hline A1 & 360 & 5 & 9 & Rectangular & $\begin{array}{c}\text { Screw } \\
\text { arris }\end{array}$ & B1 & 80 & 90.6 & 370 \\
\hline A2 & 360 & 5 & 9 & Zigzag & cross & B2 & 80 & 90.6 & 370 \\
\hline A3 & 360 & 5 & 9 & Trapezoid & $\begin{array}{c}\text { section } \\
\text { shape }\end{array}$ & B3 & 80 & 90.6 & 370 \\
\hline
\end{tabular}

Where $v_{x}, v_{y}, v_{z}$ are speed of $\mathrm{x}, \mathrm{y}, \mathrm{z}$ directions; $\tau_{i j}$ is shearing stress; $\tau_{i i}$ is normal stress; $p$ is pressure; $\rho$ is density of fluid; $C_{p}$ is specific heat capacity; $T$ is temperature.

\section{Geometrical model}

Table 1 The parameters of geometric model

Mesh superpostion technology ${ }^{[13]}$ is applied to the flow field simulation which contains the rotor. Firstly, we mesh the melt area and moving parts separately, and then put them together to generate a new kind of combined grid file by specific rules. So the movement of moving parts on the channel can be simulated directly. It only gives one combined grid figure because that the difference of depth of the screw slot is not clear. In Fig.1, AB1 is the model that combines A1 and B1, as well as AB 2 and $\mathrm{AB} 3$ are also the model that combines the corresponding screws and melt flow area.

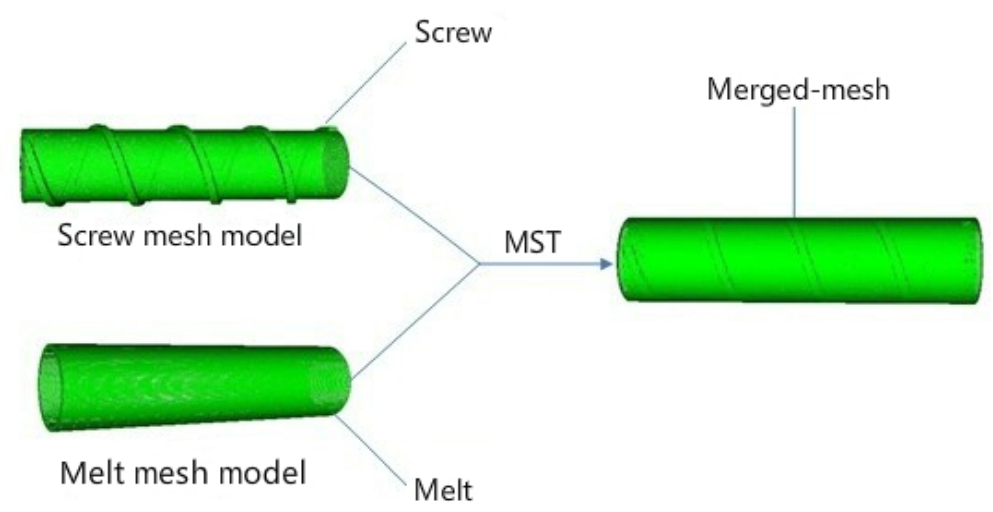

Fig.1 The generating schematic plot of meshing group of AB1 


\section{Material parameters and boundary conditions}

\section{Material parameters}

Material parameters. The rheological behavior that the wooden plastic composites behaves in squeezing and forming process mainly includes: shear flow, sticky flow and flexibility. In the process, cut flow is the dominant form of the material flow. The main factors that influence the melt viscosity are temperature and shear rate. The viscosity data in different shear rate and temperature through different experimental condition sets are obtained from the rheological capillary instrument. The basic parameters are listed in table2 and experimental results are shown in table 3.

Table 2 The material parameters

\begin{tabular}{cccc}
\hline Parameters & Units & Symbols & Values \\
\hline Melt density & $\mathrm{kg} \cdot \mathrm{m}^{-3}$ & $\rho$ & $1.3 \times 10^{3}$ \\
Melt thermal conductivity & $\mathrm{J} \cdot \mathrm{m}^{-1} \cdot \mathrm{s}^{-1} \cdot{ }^{\circ} \mathrm{C}^{-1}$ & $\mathrm{k}$ & 0.21 \\
Melt specific heat capacity & $\mathrm{kJ} \cdot \mathrm{kg}^{-1} \cdot{ }^{\circ} \mathrm{C}^{-1}$ & $\mathrm{C}_{p}$ & 1.10 \\
Screw density & $\mathrm{kg} \cdot \mathrm{m}^{-3}$ & $\rho^{\prime}$ & $8.03 \times 10^{3}$ \\
Screw thermal conductivity & $\mathrm{J} \cdot \mathrm{m}^{-1} \cdot \mathrm{s}^{-1} \cdot{ }^{\circ} \mathrm{C}^{-1}$ & $\mathrm{k}^{\prime}$ & 16.27 \\
Screw specific heat capacity & $\mathrm{kJ} \cdot \mathrm{kg}^{-1} \cdot{ }^{\circ} \mathrm{C}^{-1}$ & $\mathrm{C}_{p}^{\prime}$ & 0.5024 \\
\hline
\end{tabular}

Table 3 The shear rate and intrinsic viscosities of the PVC wood-plastics composite material

\begin{tabular}{cccc}
\hline \multirow{2}{*}{ Shear rate(1/s) } & \multicolumn{3}{c}{ Viscosities(Pa•s) } \\
& $170^{\circ} \mathrm{C}$ & $180^{\circ} \mathrm{C}$ & $190^{\circ} \mathrm{C}$ \\
\hline 100 & 1721 & 1146 & 1271 \\
158.5 & 1713 & 1052 & 974.8 \\
251.2 & 1522 & 963.7 & 874.3 \\
398.1 & 1178 & 785.3 & 734.1 \\
631 & 968.6 & 732.4 & 597.4 \\
1000 & 761.3 & 658.3 & 523.6 \\
\hline
\end{tabular}

Viscosity model. The viscosity of PVC wooden plastic composite materials reduces with the shear rate increasing. It leads to the diluted cut shear which present a clear features of pseudoplastic flow, and the viscosity and elastic benefit of materials are relatively weak. Relatively, in the range of normal shear rate $\left(10^{2} \sim 10^{4} \mathrm{~s}^{-1}\right)$ of squeezing and forming process, Power Law model has good accuracy and easy to calculate, so it is widely used. As a result, the subject uses Power Law model which is widely used in engineering calculation as constitutive model equation to simulation, such as Eq.4.

$$
\eta=K(\lambda \dot{\gamma})^{n-1}
$$

Where $\eta$ is viscosity, unit: $P a \bullet s$; $K$ is viscosity coefficient, which is usually zero shear viscosity of the polymer melt, unit: $P a \bullet s ; \lambda$ is flabby time, unit: $\mathrm{s} ; \dot{\gamma}$ is cut shear rate, unit: $\mathrm{s}^{-1} ; n$ is power law index, also called flow index and non-Newton index. It is non-dimensional index.

As for the actual squeezing and molding process situation, temperature also makes a huge difference on the viscosity besides shear rate, the general viscosity model is as equation 5 shown below.

$\eta=H(T) \eta_{0}(\dot{\gamma})$

Where $H(T)$ is temperature expression; $\eta_{0}(\dot{\gamma})$ is viscosity expression in temperature $T_{\alpha}$. 
$\eta_{0}(\dot{\gamma})$ is provided by Power Law, and $H(T)$ is provided by

Arrhenius Approximate Law. Arrhenius Approximate Law is as equation 6 shown below.

$H(T)=\exp \left[-\alpha\left(T-T_{\alpha}\right)\right]$

Where $\alpha$ is active energy factor; $T_{\alpha}$ is reference temperature.

In the end, the material viscosity parameters can be got by using polymath module in POLYFLOW software.

\begin{tabular}{cccc}
\multicolumn{4}{c}{ Table 4 The parameters of the rheological property } \\
\hline Parameters & Units & Symbols & Values \\
\hline Viscosity factor & & & 1596.5 \\
& $\mathrm{~Pa} \cdot \mathrm{S}$ & $K$ & 7 \\
Relaxation time & $\mathrm{s}$ & $\lambda$ & 1 \\
Power law index & & $\mathrm{n}$ & 0.665 \\
Activation energy factor & ${ }^{\circ} \mathrm{C}^{-1}$ & $\alpha$ & 0.0025 \\
Reference temperature & ${ }^{\circ} \mathrm{C}$ & $T_{\alpha}$ & 180 \\
\hline
\end{tabular}

\section{Boundary conditions}

POLYFLOW ${ }^{[14]}$ has many types of boundary conditions. In order to avoid simulation divergent or getting the wrong result, boundary conditions have to be set reasonably. For the $3 \mathrm{~d}$ non-Newton and non-isothermal fluid flow fields in the single screw extrusion molding are focused in this work, the flow boundary conditions, thermal boundary conditions and the moving parts moving conditions need to be set. Combined with the assumptions made before, the boundary conditions ${ }^{[15]}$ were set up as follows:

Flow boundary conditions.

(1) Entrance boundary conditions: set the entrance boundary condition as flow boundary, the screw speed was 20rad/min, entrance volume flow is $5.2469 \times 10^{-5} \mathrm{~m}^{3} / \mathrm{s}$;

(2) Outlet boundary conditions: set the outlet boundary conditions as OUTFLOW;

(3) The barrel inner wall surface boundary conditions: set the wall as no slip boundary condition. Normal velocity and tangential velocity is 0 , that is $v_{n}=0, v_{s}=0$;

(4) Melt and screw contact surface: melt and screw take coaxial and the same speed exercise. The rotating speed is set as $20 \mathrm{rad} / \mathrm{min}$;

\section{Thermal boundary conditions.}

(1) Entrance boundary conditions: the entrance temperature is set as $180^{\circ} \mathrm{C}$.

(2) Outlet boundary conditions: the outlet has no boundary condition.

(3) The barrel inner wall surface boundary conditions: the barrel inner wall surface temperature is set as $200^{\circ} \mathrm{C}$.

(4) Melt and screw contact surface: heat insulation.

\section{The moving parts screw moving conditions.}

The screw is set as moving parts(Moving part\#1). The coordinates of rotation center is $(0,0,0)$, and the coordinates of central axis is $(0,0,1)$. The origin of coordinates is in the center of the melt entrance. The screw rotating speed is set as $20 \mathrm{r} / \mathrm{min}$.

\section{Simulation results and analysis}

\section{The pressure field}

Fig.2, 3 and 4 show the whole melt flowing distribution map along the main flow direction, the pressure field distribution map when $\mathrm{y}=0$ and the pressure distribution along the $\mathrm{Z}$ axis when $\mathrm{x}=45.3$, the screw section shape changes and other melt conveying section parameters doesn’t change. 


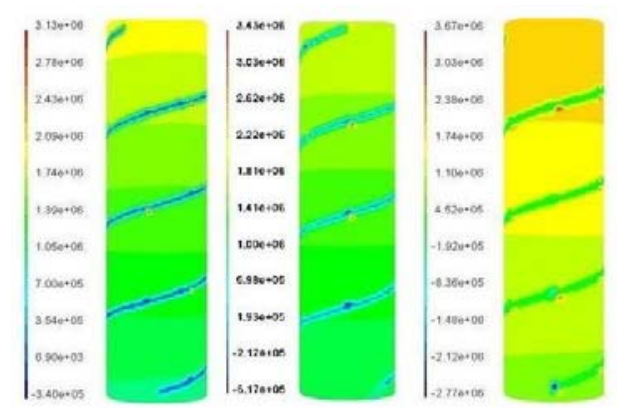

Fig.2 The total pressure distribution of model AB1-3

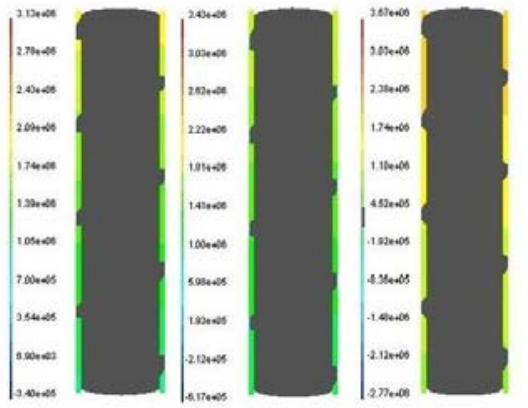

Fig.3 The pressure distribution on the surface of " $y=0$ " of model AB1-3

Fig. 2 and Fig. 3 show that the melt outlet pressure is higher than the inlet. And the pressure level increases gradually along the extrusion direction. The screw thrust face pressure is higher and the back pressure is lower while the pressure mutates at the edge of screw. The biggest pressure of model $\mathrm{AB} 1, \mathrm{AB} 2, \mathrm{AB} 3$ are both at the outlet of melt, which are $2.23 \mathrm{MPa}, 2.45 \mathrm{MPa}, 2.66 \mathrm{MPa}$. The outlet pressure of model AB1 is the lowest and the outlet pressure of model AB3 is the highest.

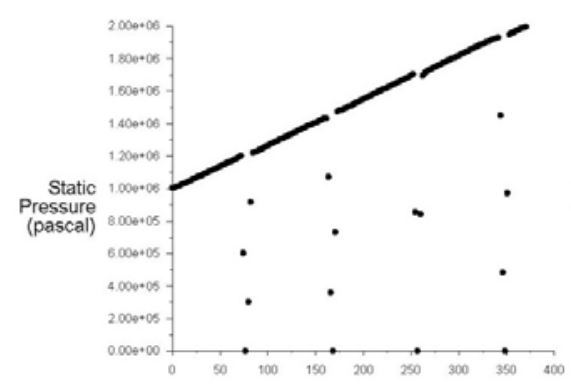

(a) $\mathrm{AB} 1$

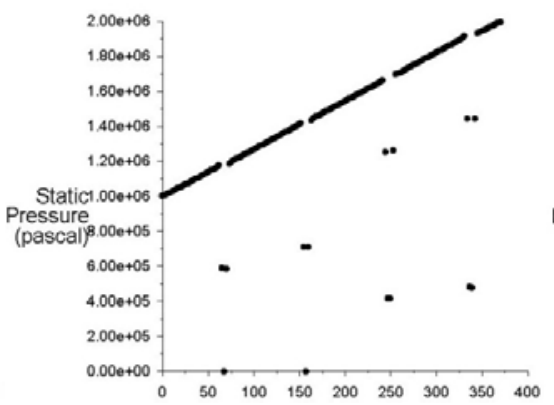

(b)AB2

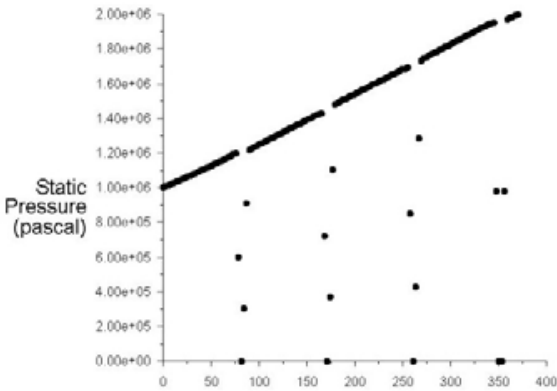

(c)AB3

Fig.4 The pressure distribution along $\mathrm{z}$-axis of model AB1-3 when $\mathrm{x}=45.3$

Fig. 4 shows that melt pressure increases along the extrusion direction. The trend that the figures reflect is almost the same, so the effect of the shape of screw section on the melt internal pressure is not obvious.
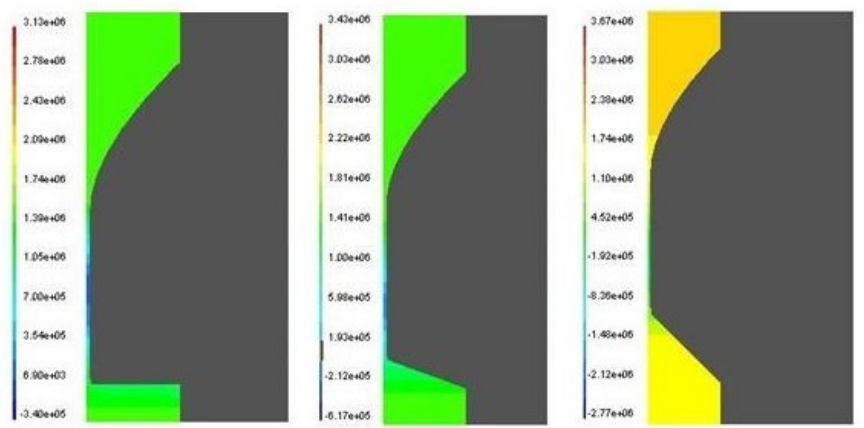

Fig.5 The pressure distribution nearby screw

Fig.5 shows that pressure gradient is exist in clearance of top of screw and barrel inside, of which the pressure of middle part is the lowest and increasing to the ends. The overall pressure distribution in the clearance is the same as the screw shape. Pressure gradient changes with the screw shape. The trapezoid pressure gradient is lowest and the pressure near the trapezoidal screw is higher than the pressure near the rectangular and serrated screw.

\section{Temperature field analysis}

Fig. 6 is the temperature distribution map. Fig.7 is the temperature distribution enlargement map of the second screw groove. Fig. 8 is the screw surface temperature distribution map. Fig.9 is the 
temperature distribution curve about the line that parallells to the $\mathrm{Z}$ axis when $\mathrm{x}=40,42,43,44,45$. All the figures are with the screw arris cross section shape changes in the $y=0$ section.

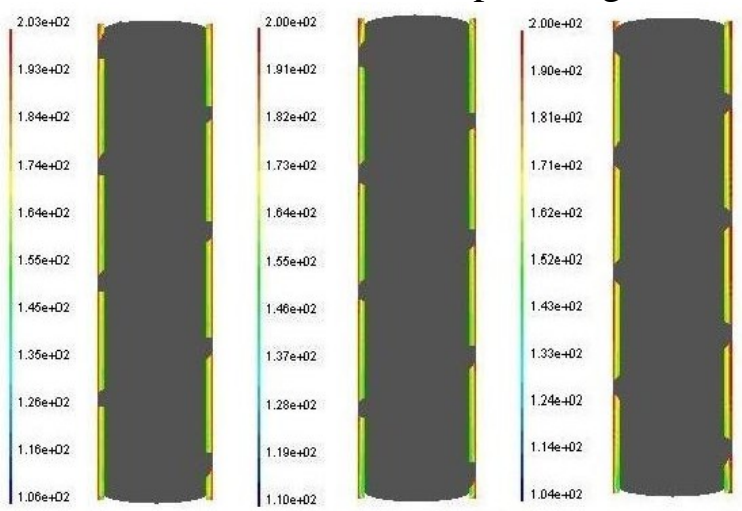

Fig.6 The temperature distribution on the surface of " $y=0$ " of model AB1-3

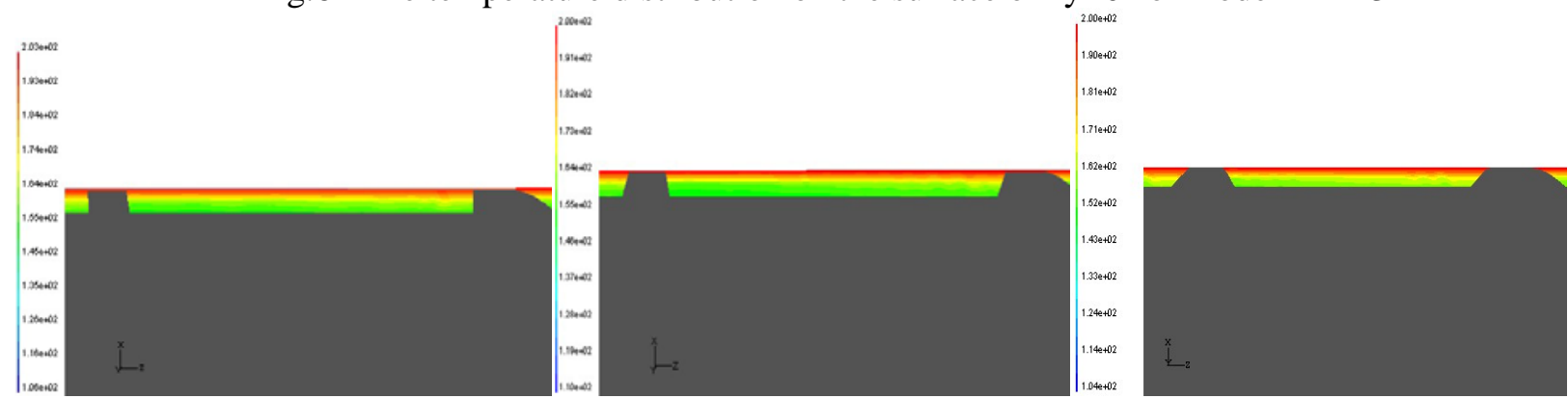

Fig.7 The temperature distribution on the second screw channel which is on the surface of " $y=0$ " of model AB1-3

Above figures shows that the temperature distribution decreases gradually from the outside to the inside along the radial direction. And the inner cylinder wall melt temperature in the channel is the highest while the melt temperature in the screw surface is the lowest. In the screw groove, the temperature has tendency to increasing along the parallel to the extrusion direction, which the screw back surface temperature is higher than that of the screw propulsion. The high temperature layer is relatively thin and the layer of low temperature is relatively thick on the screw pushing surface, while the non -screw propelling surface is on the contrary.

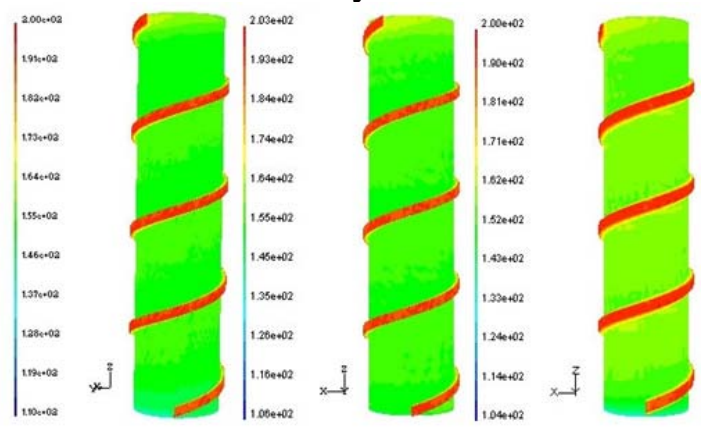

Fig.8 The temperature distribution on the surface of the screw of model AB1-3

For each screw, the surface temperature distribution has gradually increased along the extrusion direction. For screws with different section shapes, the highest screw temperature is $195^{\circ} \mathrm{C}$ and the highest screw groove temperature is $156^{\circ} \mathrm{C}$ when the screw section shape is rectangular; the highest screw temperature is $197^{\circ} \mathrm{C}$ and the highest screw groove temperature is $157^{\circ} \mathrm{C}$ when the screw section shape is zigzag; the highest screw temperature is $198^{\circ} \mathrm{C}$ and the highest screw groove temperature is $158^{\circ} \mathrm{C}$ when the screw section shape is trapezoid. 


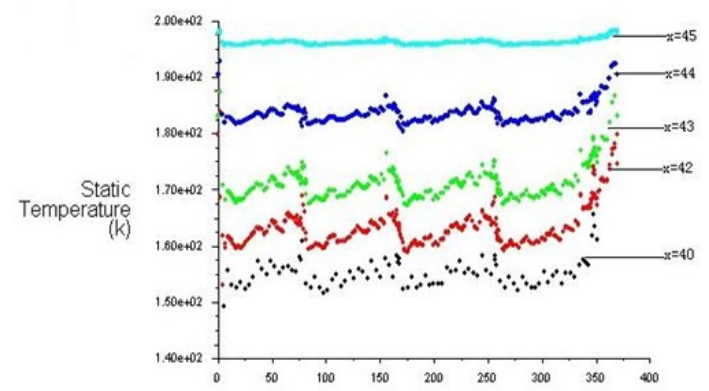

(a)AB1

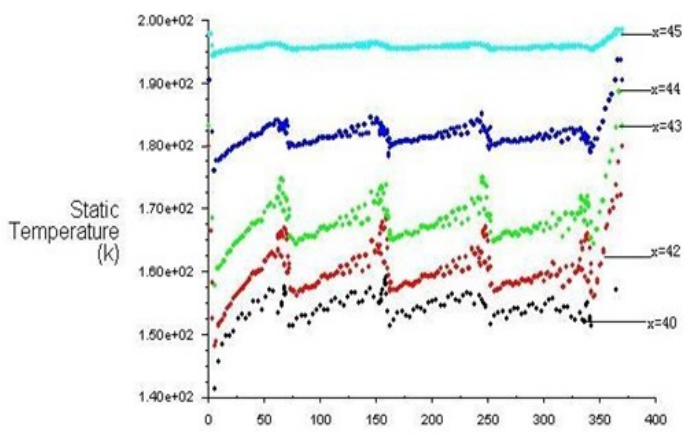

(b)AB2

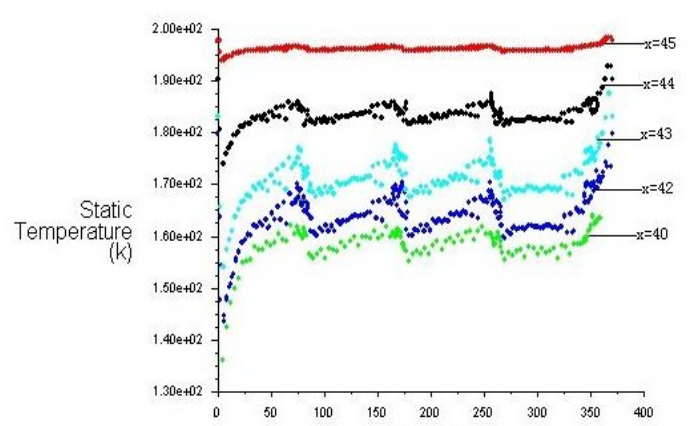

(c) $\mathrm{AB} 3$

Fig.9 The temperature distribution curve on the five lines of model AB1-3

It can be seen that the average melt temperature in rectangular section is about $155^{\circ} \mathrm{C}$, the average melt temperature in zigzag section is about $158^{\circ} \mathrm{C}$ and the average melt temperature in trapezoidal section $162^{\circ} \mathrm{C}$ while $\mathrm{x}=40$. So it can be conclude that trapezoidal section shape is the best shape for the melt heat transferring.

\section{Analysis of velocity field}

Fig.10 and Fig.11show that the velocity contour and the second screw groove velocity distribution enlargement in the $\mathrm{y}=0$ section.
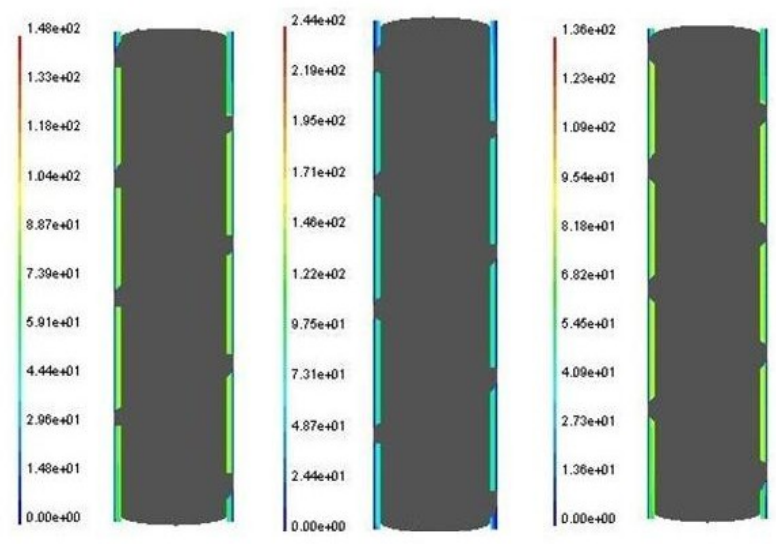

Fig.10 The velocity distribution on the surface of " $y=0$ " of model AB1-3 


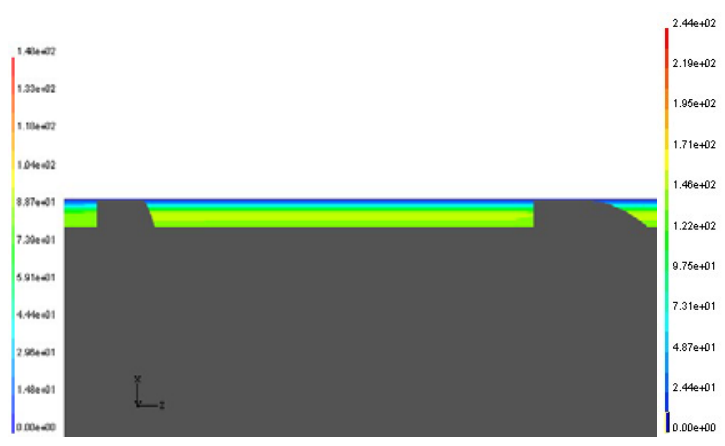

(a)AB1

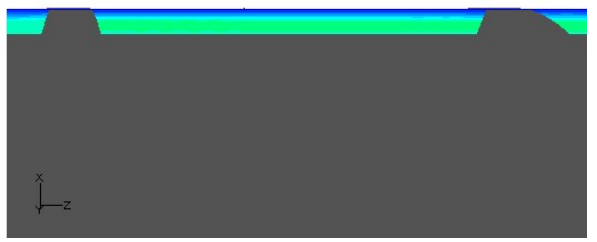

(b)AB2

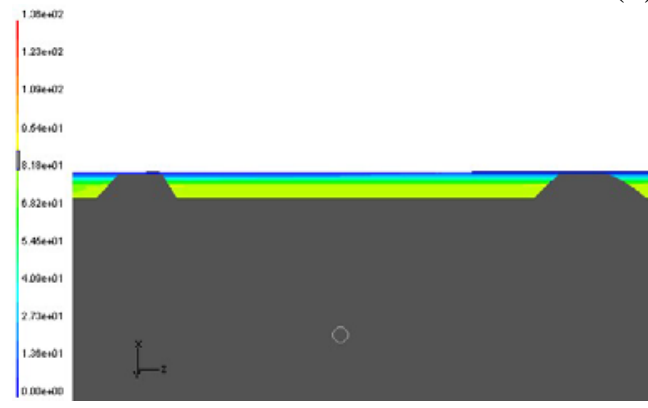

(c)AB3

Fig.11 The velocity distribution on the second screw channel which is on the surface of " $y=0$ " of model AB1-3

The melt flows in the screw groove are both along the extrusion direction and the circumferential rotation with the screw rotation. The figure above is velocity distribution map. The near surface melt speed is higher while the cylinder inner wall surface melt speed is relatively lower. By comparison and analytic study on the figures above, along the radial direction, for $\mathrm{AB} 1$ and $\mathrm{AB} 2$, the velocity firstly increases, the screw surface speed decreases slightly, the cylinder inner wall speed is the minimum and the central channel speed is the maximum. But for AB3, along the radial direction, the speed increases gradually, the cylinder inner wall speed is the minimum, the screw surface speed is the maximum.

\section{Conclusions}

This paper gets the viscosity of PVC wood plastic composites under different temperatures and shear stress through the experiment and the unknowns in the equations by the POLYMAT of POLYFLOW. It conducts the numerical simulation by POLYMAT and analysis the simulation results by FLUENT/Post software. We can conclude that the screw section shape have an influence on screw melt conveying section pressure field, temperature field and velocity field. The main conclusions are as follows: (1) the outlet pressure with rectangular screw cross-section shape is the minimum and outlet pressure with trapezoidal screw section shape is the maximum, but the effect of screw section shape on melt internal pressure is not obvious; (2) screw with trapezoidal cross section shape can improve melt heat transferring; (3) the melt velocity with trapezoidal screw section shape changes gradually, while the melt velocity with the other shapes mutates.

\section{References}

[1] Qingwen Wang, Weihong Wang. Wood-plastic Composites and Products[M]. BeiJing: Chemical Industry Press, 2006.(In Chinese)

[2] Fan Cheng Shen, Run Li Jia. Research Progress and Prospect of Wood-Plastic Composites[J]. Plastics Additives. 2010(01): 5-9.(In Chinese)

[3] Yong Sheng Zhao, Ping Xue, Fu Hua Zhu, et al. Process in Study on Wood Flour and Plastic Composites[J]. Plastics Manufacture. 2006(06): 67-71.(In Chinese) 
[4] Zheng Hong Zhang. Study on the compounding and properties of PVC/WOOD flour composites[D]. Zhejiang University of Technology, 2009.(In Chinese)

[5] Zi Qiang Li. Study on the preparation and properties of Wood-Plastic composites[D]. Shandong University, 2009.(In Chinese)

[6] Min He. Numerical simulation of the mixing process 3D flow field on synchronous rotor mixer[D]. 2010.(In Chinese)

[7] Wenqi Ma, Hongyi Sun. Basics and Application of Plastic Forming Simulation Software Technology[M]. BeiJing: China Railway Publishing House, 2006.(In Chinese)

[8] Gang Feng. Research Progress in Numerical Simulation of Screw Extruder Process[J]. Engineering Plastics Application. 2012(04): 96-99.(In Chinese)

[9] Hui Liu. Wood-plastic composite and special single-screw extruder[D]. Wu Han: Wuhan University of Technology, 2012.(In Chinese)

[10] Jizhao Liang. Polymeric Materials processing Rheology[M]. BeiJing: National Defence Industry Press, 2008.(In Chinese)

[11] Ming Jun Yuan, Fu Hua Zhu. Deformation ,Orientation and Melting of Solid Particle in Single Screw Extrusion III. Theory and Calculation of Solid Particle Melting Process[J]. CHINA PLASTICS. 2000(01): 97-104.(In Chinese)

[12] Lindt J T. A dynamic melting model for a single-screw extruder[J]. Polymer Engineering and Science. 1976, 16(4): 284-291.

[13] Tao Fan, Zuo Bing Chen, Jia Jia Du, et al. The Effects of Spiral Groove Depth on PVC Wood-plastics Single-screw Extruder Melting Section Melting Process[J]. Journal of Wuhan University of Technology. 2015, 1(37): 125-130.(In Chinese)

[14] Xin Qian, Wangding Xu, Yangfu Jin. Basics and Application in Plastic Processing of POLYFLOW[M]. BeiJing: Chemical Industry Press, 2010.(In Chinese)

[15] Xin Qian, Yu Zhuo Gao, Jian Zhao, et al. CAE Technology in Plastics Molding[M]. BeiJing: China Light Industry Press, 2011.(In Chinese) 